\title{
One-sided sustainability tests with amenities, and changes in technology, trade and population
}

\author{
John C.V. Pezzey ${ }^{\mathrm{a}, \mathrm{b}, *}$ \\ ${ }^{a}$ Centre for Resource and Environmental Studies, Australian National University, Canberra, ACT 0200, Australia \\ ${ }^{\mathrm{b}}$ Department of Economics, University of Bath, Bath BA2 7 AY, UK
}

Received 29 April 2002; revised 4 March 2003; accepted in revised form 2 October 2003

\begin{abstract}
If an economy with multiple consumption goods (including environmental amenities) uniquely maximises present value with constant discounting, it is unsustainable at some time if either of two measures - augmented net investment, or the change in augmented green net national product - are zero or negative then. "Augmented" denotes that time is treated as a productive stock, which includes in each measure the value of future, exogenous changes in technology or terms of trade. Adjustments are found to make each measure a test for individual sustainability when population grows exogenously. The practical and philosophical rationale for testing sustainability in a present-value-maximising, and therefore fully prescribed, development path is discussed.
\end{abstract}

(C) 2003 Elsevier Inc. All rights reserved.

Keywords: Sustainability; Optimality; Net investment; Green net national product; Population; Green accounting

\section{Introduction}

There is now a well-established empirical literature on measuring the sustainability of national economies using "green" adjustments to aggregate income, investment or wealth data. A wellknown early calculation was by Repetto et al. [38] for Indonesia, followed for example by Solorzano et al. [40] for Costa Rica, Pearce and Atkinson [26] for 18 countries worldwide, and Pearce et al. [28] for the UK. Examples of more recent work are by Atkinson et al. [11], Hamilton and Clemens [18] and Neumayer [25]. Despite this, there is still no formal, general, published

\footnotetext{
${ }^{*}$ Corresponding author. Centre for Resource and Environmental Studies, Australian National University, Canberra, ACT 0200, Australia. Fax: +61-26125-0757.

E-mail address: pezzey@cres.anu.edu.au.
} 
statement and proof of the theoretical connection between sustainability, and measures of 'net investment', 'genuine saving' or 'aggregate wealth'.

This claim might seem surprising, given the extensive theoretical literature on sustainability, and it is true only when strictly confined to one definition of sustainability, a word notorious for dozens of definitions. Our definition, which applies only to a representative-agent economy and will be formally stated and discussed later, is this. An economy is sustainable at some time $t$, if and only if the representative agent's utility (well-being) $U(t)$ then does not exceed the maximum level of utility $U^{m}(t)$ which can be sustained forever from $t$ onwards, given the capital stocks existing at $t$. This definition is implied by, but does not imply, the well-known condition that the agent's utility be forever non-declining from $t$ onwards [31,33].

Existing literature relevant to our definition of sustainability has one or more drawbacks, being informal (e.g. [26, p. 104; 28, p. 42]), unpublished [16,32], confined to a very specific economy [11, p. 62, p. 68], confined to the uninteresting, perhaps non-existent case where an optimal development path already satisfies Hartwick's rule [25, p. 151], or confined to the autonomous case, where production possibilities do not depend directly on time (most of the above). Asheim [5], and later Vellinga and Withagen [45, p. 511] and Aronsson and Lofgren [1, p. 213], noted that positive or zero net investment at an instant does not imply sustainability then. But none of these authors showed what can be implied from measuring net investment.

The main contribution here is to prove a pair of one-sided unsustainability tests in each of three perfectly competitive, present-value-maximising, deterministic economies with multiple consumption goods (or 'extended consumption') including environmental amenities, and a constant utility discount rate. We start with the autonomous case, and show that at any time, either negative or zero net investment (including changes in non-marketed environmental resource stocks), or falling or constant 'green' net national product (GNNP) measured with suitably indexed prices, implies unsustainability then. They are one-sided tests because they show only unsustainability, not sustainability.

The second economy in which these tests, suitably reframed, are shown to hold, has nonautonomous production (due to exogenous changes in technology or terms of trade, two important features of most real economies), but still has constant population. The reframing comprises 'augmenting' net investment or GNNP, by adding to each of these measures an extra term which values all future exogenous changes in the production set. The third economy allows also for exogenous population growth, an important reality for many developing countries, at least in the short term. This causes complications, because population enters both the maximand of present value and the production set, and sustainability is redefined in terms of individual rather than total utility. We show, albeit only for the case of exponential population growth, that recomputing net investment or GNNP change by just substituting per capita for total variables does not give a measure of unsustainability; further adjustments must be made.

The structure of the paper is as follows. Section 2 describes the autonomous economy in Asheim and Weitzman [10], hereafter AW; defines and discusses our chosen meaning of sustainability; and then uses AW's results to establish the one-sided sustainability tests and related results in this economy. Section 3 gives sustainability and other results for the case of nonautonomous production, and Section 4 gives the sustainability tests for the case of exogenous population growth. These sections also show how several well-known results are special cases within our general framework. Section 5 concludes by considering how practicable the theory is, 
and the apparent paradox of why sustainability measures should be of interest when present value maximisation already prescribes a unique development path, and so apparently leaves no role for sustainability concerns.

\section{Testing for sustainability in the autonomous, constant population case}

\subsection{Recapitulation of the Asheim-Weitzman economy and results}

The economy we develop to investigate sustainability is the continuous-time, representativeagent, competitive, time-autonomous, deterministic, constant-population economy in $\mathrm{AW}$, which contains all details omitted in what follows. At any time $t \geqslant 0$, vector $\mathbf{C}(t)$ denotes "multiple consumption goods": everything, including environmental amenities, that influences the agent's well-being $U(\mathbf{C}(t))$, where $U$ is a given concave and non-decreasing (instantaneous) utility function with continuous second derivatives. (In Section 4 we will distinguish individual utility $u($.$) from total utility U($.$) , but for now this distinction can be ignored.) The economy's$ endogenous, productive stocks of environmental resources, and built, human, knowledge and foreign capital, form a vector $\mathbf{K}(t)$, of maybe different dimension to $\mathbf{C}(t)$. Some stocks in $\mathbf{K}$, such as natural resource stocks, may yield amenity services to agents, and thus also be part of $\mathbf{C}$; but separate prices would apply to the stock itself as a source of amenity services, and to the depletion of the stock as a future factor of production and source of amenity.

We assume that the economy chooses paths of consumptions $\mathbf{C}(t)$ and net (after-depreciation) investments $\mathbf{I}(t):=\dot{\mathbf{K}}(t)$ within a smooth, convex production possibilities set $S(\mathbf{K})$, with $\mathbf{K}(0)=$ $\mathbf{K}_{0}$ given, to maximise intertemporal welfare, defined as the present value (PV) of utility using a constant discount rate $\rho>0$ :

$$
\begin{array}{rl}
\operatorname{Max}_{\mathbf{C}, \mathbf{I}} & W(\{\mathbf{C}(t)\}):=\int_{0}^{\infty} U[\mathbf{C}(t)] e^{-\rho t} \mathrm{~d} t^{1} \\
\text { s.t. } & {[\mathbf{C}(t), \mathbf{I}(t)] \in S(\mathbf{K}(t)) .}
\end{array}
$$

All environmental and other externalities here have implicitly been already internalised by policies not represented in the model. We call this maximising path PV-optimal, or optimal for short. The assumption of PV-optimality is crucial but rather paradoxical in the context of sustainability, as discussed in Section 5.

The current-value Hamiltonian of problem (1) is

$$
H(\mathbf{C}, \mathbf{I} ; \boldsymbol{\Psi}):=U(\mathbf{C})+\boldsymbol{\Psi} \cdot \mathbf{I},
$$

where $\boldsymbol{\Psi}(t)$ are shadow investment prices, and we use AW's equation (5) that on the optimal path, denoted by asterisks $(*)$ :

$$
\dot{H}^{*}(t)=\rho \mathbf{\Psi}(t) \cdot \mathbf{I}^{*}(t)=\rho\left[H^{*}(t)-U\left(\mathbf{C}^{*}(t)\right)\right] \text { by (2) for all } t .
$$

As in AW, real prices for consumption and investment vectors are

$$
\mathbf{P}(t):=\left[\nabla U\left(\mathbf{C}^{*}\right)(t)\right] /[\lambda(t) \pi(t)] \text { and } \mathbf{Q}(t):=\boldsymbol{\Psi}(t) /[\lambda(t) \pi(t)] .
$$

\footnotetext{
${ }^{1}$ Many authors call $U($.$) 'welfare' rather than (instantaneous) utility, and a few call W($.$) 'utility' rather than$ (intertemporal) welfare, both of which can cause confusion.
} 
where $\lambda(t)>0$ is the marginal utility of current expenditures, and $\pi(t)>0$ is a price deflator or index satisfying the Divisia condition:

$$
\pi(t) \text { is s.t. } \dot{\mathbf{P}}(t) \cdot \mathbf{C}^{*}(t)=0 \text { for all } t .^{2}
$$

The real interest rate is then defined as

$$
R(t)=\rho-\dot{\lambda}(t) / \lambda(t)-\dot{\pi}(t) / \pi(t) .
$$

The final AW definition needed is Green net national product (GNNP) in real Divisia prices, defined as

$$
\mathrm{GNNP} \equiv Y(t):=\mathbf{P}(t) \cdot \mathbf{C}^{*}(t)+\mathbf{Q}(t) \cdot \mathbf{I}^{*}(t),
$$

with $\mathbf{Q} \cdot \mathbf{I}^{*}$, the real value of net investments, being called here just net investment (also often now called genuine saving, after Hamilton [15]). We will use AW's Proposition 3, that $\dot{Y}(t)$, the time derivative of GNNP, always equals the real interest rate $R(t)$ times net investment $\mathbf{Q}(t) \cdot \mathbf{I}^{*}(t)$ :

$$
\text { For all } t, \dot{Y}(t)=R(t) \mathbf{Q}(t) \cdot \mathbf{I}^{*}(t)=R(t)\left[Y(t)-\mathbf{P}(t) \cdot \mathbf{C}^{*}(t)\right] \text { by }(7) \text {. }
$$

\subsection{The one-sided unsustainability tests}

In deriving our sustainability tests in the AW economy just described, we first define the (maximum) sustainable utility $U^{m}(t)$, which depends on time $t$ via the economy's stocks $\mathbf{K}(t)$, in the obvious way as

$$
\begin{aligned}
U^{m}(t):=\max & U \\
\text { s.t. } & U(\mathbf{C}(s)) \geqslant U \text { for all } s \geqslant t .
\end{aligned}
$$

We then define:

an economy is sustainable at time $t \Leftrightarrow U(\mathbf{C}(t)) \leqslant U^{m}(t)$.

Using this definition ducks all debate about rival meanings of sustainability (see [30] for a historical collection). Contributing to that prolific (and often semantic) debate is not our aim; we merely claim that (9) and (10) form a possible and fairly natural mathematical translation of the word 'sustainable' into the context of our representative-agent, smoothly substitutable model. For by (10), unsustainability at $t$ means $U(\mathbf{C}(t))>U^{m}(t)$; so by (9) utility must decline (to below $\left.U^{m}(t)\right)$ at some future time, an outcome that would also be 'unsustainable' by the well-known 'forever non-declining utility' definition in [30]. (But note that the economy's development path must be efficient for definition (10) to make sense, for in an inefficient economy, current $U(t)$ could be less than $U^{m}(t)$ and yet still be unsustainable.) Our key result is then:

Proposition 1. The one-sided unsustainability tests.

\footnotetext{
${ }^{2}$ Note two points about this condition. First, standard national accounting practice uses a deflator defined not by just consumption prices $\mathbf{P}$, but by a more complete price vector including investment and international trade. However, standard practice on deflators is not aimed at using the change in real national product as a measure of welfare improvement, and so does not apply here. Second, from (4), $\mathbf{P}$ includes the shadow price of the flow of amenity services yielded by any environmental stock, but not the shadow price of the stock itself.
} 
Extra assumption. The optimal utility path is unique and not constant, and the interest rate $R$ is positive. ('Extra assumptions' are always those needed in addition to the definition of the AW economy in Section 2.1.)

Result. At $t$, non-positive net investment or non-rising GNNP means the optimal economy is unsustainable at $t$. That is:

$$
\mathbf{Q}(t) \cdot \mathbf{I}^{*}(t) \leqslant 0 \text { or } \dot{Y}(t) \leqslant 0 \Rightarrow U\left(\mathbf{C}^{*}(t)\right)>U^{m}(t) .
$$

Proof. This is technical but important to follow, to see why the assumptions of uniqueness and non-constancy are needed. The proof varies slightly for the two conditions. Starting with the first, on the sign of net investment:

$$
\begin{aligned}
& \mathbf{Q}(t) \cdot \mathbf{I}^{*}(t) \leqslant 0 \Rightarrow \lambda(t) \pi(t) \mathbf{Q}(t) \cdot \mathbf{I}^{*}(t) \leqslant 0 \Rightarrow \mathbf{\Psi}(t) \cdot \mathbf{I}^{*}(t) \leqslant 0 \text { by }(4) \\
& \quad \Rightarrow H^{*}(t) \leqslant U\left(\mathbf{C}^{*}(t)\right) \text { by }(3) .
\end{aligned}
$$

Now $(d / d s)\left[-H^{*}(s) e^{-\rho(s-t)}\right]=\left[\rho H^{*}(s)-H^{*}(s)\right] e^{-\rho(s-t)}=\rho U\left(\mathbf{C}^{*}(s)\right) e^{-\rho(s-t)}$, where the second equality also uses (3). Integrating this from $t$ to $\infty$ gives

$$
\begin{aligned}
& H^{*}(t)=\rho \int_{t}^{\infty} U\left(\mathbf{C}^{*}(s)\right) e^{-\rho(s-t)} d s, \\
& \Rightarrow H^{*}(t) / \rho=\int_{t}^{\infty} H^{*}(t) e^{-\rho(s-t)} d s=\int_{t}^{\infty} U\left(\mathbf{C}^{*}(s)\right) e^{-\rho(s-t)} d s=: W^{*}(t),
\end{aligned}
$$

where from (1), $W^{*}(t)$ is maximised welfare at time $t$. (Note how the last two steps require the utility discount rate $\rho$ to be constant.) The non-constancy and uniqueness of utility on the optimal path then mean that

$$
H^{*}(t)>U^{m}(t) \text {. }
$$

Otherwise, following the feasible constant utility path $U(s)=U^{m}(t)$ for all $s \geqslant t$ would, using (13), give at least as much PV as the (non-constant) optimal utility path, a contradiction of a unique optimum. Combining (12) and (14) gives the required result that current $U\left(\mathbf{C}^{*}(t)\right)$ is unsustainable:

$$
U\left(\mathbf{C}^{*}(t)\right) \geqslant H^{*}(t)>U^{m}(t) \text { as required in }(11) .
$$

Starting with $\dot{Y}$, the sign of GNNP change, we have that if $R(t)>0$ :

$$
\dot{Y}(t) \leqslant 0 \Rightarrow R(t) \mathbf{Q}(t) \cdot \mathbf{I}^{*}(t) \leqslant 0 \text { by }(8) \Rightarrow \mathbf{Q}(t) \cdot \mathbf{I}^{*}(t) \leqslant 0 .
$$

The rest of the proof then follows as before.

Five comments on Proposition 1 will highlight its character. First, note its one-sidedness. Zero net investment or GNNP change implies unsustainability. (This is a stronger result than claimed in Hamilton and Clemens [18, p. 336], though if the optimal path is either constant or not unique, only strictly negative net investment or GNNP change implies unsustainability.) And positive GNNP change or net investment does not imply sustainability. (A counterexample was noted by Asheim [5, Section IV].) 
Second, the well-known Hartwick's rule [20] is related to, but distinct from, Proposition 1. Hartwick's rule is that if net investment $\mathbf{Q} \cdot \mathbf{I}^{*}$ is zero forever, then utility $U^{*}(t)\left(:=U\left(\mathbf{C}^{*}(t)\right)\right)$ is constant forever. (The proof is that by (4) and (3), $\rho \lambda \pi \mathbf{Q} \cdot \mathbf{I}^{*}=\dot{H}^{*}=\rho\left(H^{*}-U^{*}\right)$; hence $\left\{\mathbf{Q} \cdot \mathbf{I}^{*}=\right.$ 0 forever $\} \Rightarrow\left\{U^{*}=H^{*}\right.$ forever $\} \Rightarrow\left\{\dot{U}^{*}=\dot{H}^{*}=0\right.$ forever $\}$, where $\rho$ need not be constant.) But Hartwick's rule cannot apply to the (more general) economies in Proposition 1, where optimal utility is not constant. In particular, Hartwick's rule does not generally hold at a point in time:

$$
\left\{\mathbf{Q}(t) \cdot \mathbf{I}^{*}(t)=0 \text { at } t\right\} \Leftrightarrow\left\{\dot{U}^{*}(t)=0 \text { at } t\right\}^{3}
$$

Third, although AW's results solve the theoretical problem of translating optimisation results from utility units to real consumption units, bypassed in Hartwick [21] with an approximate 'linearisation of the Hamiltonian', finding the path $\mathbf{P}(t)$ of real consumption prices will still be difficult in practice. It requires many valuations to find the price paths of externalised, environmental services relative to marketed consumption (in common with Hartwick's linearisation), and also integration of the Divisia condition $\dot{\mathbf{P}} \cdot \mathbf{C}^{*}=0$, to make these prices 'real' relative to the extended consumption index. The net investment $\left(\mathbf{Q} \cdot \mathbf{I}^{*}\right)$ condition for unsustainability at an instant, which does not explicitly involve $\mathbf{P}$ or $\mathbf{C}^{*}$, and is thus also independent of the price index (5), should therefore be easier to compute approximately than the GNNP change $\left(\dot{Y}=(d / d t)\left(\mathbf{P} \cdot \mathbf{C}^{*}+\mathbf{Q} \cdot \mathbf{I}^{*}\right)\right)$ condition. However, an exact computation of net investment would also require valuation, to discover how optimal investment prices $\mathbf{Q}$ differ from observed, non-optimal prices. ${ }^{4}$ The distinction between the measures disappears anyway when comparing the relative measures $\mathbf{Q} \cdot \mathbf{I}^{*} / Y$ and $\dot{Y} / Y$; and if some elements of $\mathbf{Q} \cdot \mathbf{I}^{*}$ are believed to be constant, they can perhaps be omitted when computing $\dot{Y}$.

Fourth, Vincent [46] (for Malaysia) and Hanley et al. [19] (for Scotland) seem to be the only writers so far to estimate variants of both net investment and GNNP growth measures. However, some trade terms, which may be significant for such small open economies, were omitted from these analyses.

Fifth, only the $\dot{Y} \leqslant 0$ condition relies on the Divisia condition (5) used to define real GNNP. The $\mathbf{Q} \cdot \mathbf{I}^{*} \leqslant 0$ condition works even with other definitions of real prices.

\subsection{Related results}

Two other, related results follow from the AW results in Section 2.1. First, note the multiplegoods equivalent of the seminal Weitzman [48] result on the present-value equivalence of GNNP $Y$.

Proposition 2. The PV-equivalence of GNNP (after Weitzman [48])

Extra assumption. The interest rate $R$ is constant.

\footnotetext{
${ }^{3}$ A different point, shown by the counterexample in [5] but weaker than Proposition 1, is that momentarily zero net investment is not equivalent to momentary just sustainability: $\left\{\mathbf{Q}(t) \cdot \mathbf{I}^{*}(t)=0\right.$ at $\left.t\right\} \Leftrightarrow\left\{U^{*}(t)=U^{m}(t)\right\}$.

${ }^{4} \mathrm{I}$ thank a referee for this point.
} 
Result.

$$
Y(t)=R \int_{t}^{\infty} \mathbf{P}(s) \cdot \mathbf{C}^{*}(s) e^{-R(s-t)} d s,^{5}
$$

and so

$$
Y(t) / R=\int_{t}^{\infty} Y(t) e^{-R(s-t)} d s=\int_{t}^{\infty} \mathbf{P}(s) \cdot \mathbf{C}^{*}(s) e^{-R(s-t)} d s
$$

Proof. Integrate (8) from time $t$ to $\infty$ (assuming the integral converges).

We define the last integral in (16), which is effectively the present value of net returns on assets, as wealth (though note that this differs from another definition of wealth as $\mathbf{Q} \cdot \mathbf{K}$, the current value of all stocks). The time derivative of (16) shows that our wealth is momentarily constant when $Y$ is, so if the assumptions needed for Propositions 1 and 2 are true, momentarily constant wealth implies unsustainability. This calls into question a common view in the policy literature, dating at least from well-known but informally worded claims in Solow [43] and Pearce et al. [27], that momentarily non-declining wealth or 'aggregate capital' implies 'sustainability' of some kind - though of course this often may not be the kind defined by (10).

If we make the yet further restrictive assumptions that the economy in Proposition 2 is small and open (so that all investment prices are exogenous world prices) and has just one consumption good $C$, then the optimal path is no longer unique, and the converse sustainability tests in Proposition 1 do hold: that is, $\mathbf{Q} \cdot \mathbf{I}^{*}$ or $\dot{Y} \gtrless 0 \Leftrightarrow C \gtrless C^{m}$. Here $C^{m}$ is (maximum) sustainable consumption, defined analogously to sustainable utility in (9). $C^{m}$ must equal GNNP $Y$ because of the PV-equivalence result (16) and the exogeneity of prices (cf. [7, p. 38]). Asheim's [5] or Pezzey's [32] comment, that there is no exact (two-sided) test for sustainability, then no longer applies. However, with multiple consumption goods, this deduction fails unless the utility function is linear, because otherwise the Divisia price index defining prices $\mathbf{Q}$ is different on the optimal and maximum sustainable paths. Also, the result cannot work for the sum of all open economies (the world economy) where prices are no longer exogenous (Brekke [12, p. 62]).

A second extra result, building on Asheim [5] and Pezzey and Withagen [37], now shows that on an optimal development path moving towards a single (and thus unsustainable) peak, net investment must at some time give a falsely optimistic message about sustainability. Pezzey and Toman [36, Figure 4.1] showed a numerical example. This result generalises to an economy with several peaks of utility, by redefining the 'initial' time to start somewhere on the upswing leading to the last peak.

Proposition 3. The false message of positive net investment in a single-peaked economy.

\footnotetext{
${ }^{5}$ If $U(\mathbf{C})$ is homothetic, the result holds with a non-constant interest rate: $Y(t)=\int_{t}^{\infty} R(s) \mathbf{P}(s) \cdot \mathbf{C}(s) \exp \left[-\int_{t}^{s} R\left(s^{\prime}\right) d s^{\prime}\right] d s$, the multiple-goods version of Sefton and Weale [39, Eq. 8]. Without homotheticity, the Divisia index $\pi(t)$ in (5) is pathdependent, so the integral is not well-defined. A constant interest rate effectively assumes a linear homogeneous utility function $U(\cdot)$, and hence homotheticity.
} 
Extra assumption. The optimal utility path is unique and non-constant.

Result. If net investment is initially positive and utility is single-peaked $\left(\exists T^{P}>0\right.$ s.t. $\dot{U}(t) \geqslant 0$ for $\left.0 \leqslant t \lessgtr T^{P}\right)$, there is a finite time period between 0 and $T^{P}$ with net investment positive but utility unsustainable $\left(U^{*}>U^{m}\right)$.

Proof. This follows straightforwardly if tediously as a variant of the proof of Proposition 3 in [5], and is available from the author.

\section{Including changes in technology and terms of trade}

An economy's production possibilities may have direct (exogenous) dependence on time, independently of any economic choices made, from at least three common sources: technical progress; changes in world prices (including interest rates) that face a trading country; and population growth. To be useful in many practical situations, the above sustainability results should thus be extended to the time-dependent (non-autonomous) case. Except in the case of population growth where the maximand in welfare $\boldsymbol{W}$ is also time-dependent, which we consider in Section 4, the extension can be simply made in theory (though by no means in practice). We use the device developed by Pemberton and Ulph [29] of formally treating time $t$, the cause of exogenous shifts in production possibilities, as a 'productive' stock, with 'investment' in this stock being $\dot{t}=1$. We use the dagger superscript ${ }^{\dagger}$ to denote variables to which a term corresponding to time as a stock has been added, and call such variables augmented. Once the appropriate variables are augmented, the theory of Section 2 is then virtually unaltered for the non-autonomous case, as follows:

- Augmented capital stocks are $\mathbf{K}^{\dagger}:=(\mathbf{K}, t)$.

- Augmented investments are $\mathbf{I}^{\dagger}:=\dot{\mathbf{K}}^{\dagger}=(\dot{\mathbf{K}}, 1)=(\mathbf{I}, 1)$.

- The current-value Hamiltonian of problem (1) becomes

$$
H^{\dagger}\left(\mathbf{C}, \mathbf{I}^{\dagger} ; \boldsymbol{\Psi}^{\dagger}\right):=U(\mathbf{C})+\boldsymbol{\Psi}^{\dagger} \cdot \mathbf{I}^{\dagger}:=U(\mathbf{C})+\boldsymbol{\Psi} \cdot \mathbf{I}+\Psi^{t},
$$

which includes $\Psi^{t}$ as the co-state variable of $t$. It is then trivial to show from AW (so no proof is given) that the augmented version of (3) holds:

$$
\dot{H}^{\dagger *}(t)=\rho \mathbf{\Psi}^{\dagger}(t) \cdot \mathbf{I}^{\dagger *}(t)=\rho\left[H^{\dagger *}(t)-U^{*}(t)\right] \text { by (2) for all } t .
$$

- $Q^{t}(t):=\Psi^{t}(t) /[\lambda(t) \pi(t)]$ will be called the value of time, which measures the real value flow to the economy at $t$ of time passing.

- Augmented GNNP is defined as GNNP plus the value of time:

$$
Y^{\dagger}(t):=Y+Q^{t}=\mathbf{P} \cdot \mathbf{C}^{*}+\mathbf{Q}^{\dagger} \cdot \mathbf{I}^{\dagger *} \text { where } \mathbf{Q}^{\dagger}:=\left(\mathbf{Q}, Q^{t}\right) .
$$

- Augmenting relevant variables in the proof of AW's Proposition 3 gives:

$$
\dot{Y}^{\dagger}(t)=R(t) \mathbf{Q}^{\dagger}(t) \cdot \mathbf{I}^{\dagger *}(t)=R(t)\left[Y^{\dagger}(t)-\mathbf{P}(t) \cdot \mathbf{C}^{*}(t)\right] \text { by }(18) .
$$


The augmented form of Proposition 1 then follows trivially, by augmenting the relevant variables in the proof already given. It is nevertheless worth stating fully, as it is the main result of the paper.

Proposition 4. The one-sided unsustainability tests in a non-autonomous economy

Extra assumption. The optimal utility path is unique and not constant.

Result. At $t$, a non-positive augmented net investment or non-rising augmented GNNP means that the economy is unsustainable at $t$. That is:

$$
\mathbf{Q}^{\dagger}(t) \cdot \mathbf{I}^{\dagger *}(t) \leqslant 0 \quad \text { or } \quad \dot{Y}^{\dagger}(t) \leqslant 0 \Rightarrow U^{*}(t)>U^{m}(t) ;
$$

or equivalently (from (18))

$$
\mathbf{Q}(t) \cdot \mathbf{I}^{*}(t)+Q^{t}(t) \leqslant 0 \text { or } \dot{Y}(t)+\dot{Q}^{t}(t) \leqslant 0 \Rightarrow U^{*}(t)>U^{m}(t) .
$$

For completeness, the augmented form of Hartwick's rule is

$$
\mathbf{Q}(t) \cdot \mathbf{I}^{*}(t)+Q^{t}(t)=0 \text { forever } \Rightarrow \dot{U}^{*}(t)=0 \text { forever. }
$$

Propositions 2 and 3 also hold in augmented form, by respectively inserting $Y^{\dagger}(t)$ for $Y(t)$, and adding 'augmented' before 'net investment'. The one new result is the following expression for $Q^{t}$, the value of time, in terms of $Y$ and $R$ :

Proposition 5. The value of time

Result:

$$
\begin{aligned}
Q^{t}(t)= & \int_{t}^{\infty}[\partial Y(s) / \partial s] \exp \left[-\int_{t}^{s} R\left(s^{\prime}\right) d s^{\prime}\right] d s \\
& \left(=\int_{t}^{\infty}[\partial Y(s) / \partial s] e^{-R(s-t)} d s \text { if } R \text { is constant }\right)
\end{aligned}
$$

\section{Proof. See Appendix.}

$Q^{t}$ is thus forward looking and likely to be harder to calculate than normal investment prices $\mathbf{Q}$, which are in principle calculable from just current observations only if capital markets are efficient. A more intuitive example of $Q^{t}$ is in Proposition 7.

It is worth showing how the above results form a comprehensive theoretical framework for green national accounting, by using them to re-derive two well-known results in the literature as our Propositions 6 and $7^{6}$

\footnotetext{
${ }^{6}$ Another result that could be included is Asheim's [6] result on adjusting GNNP to incorporate capital gains resulting from exogenous changes in production possibilities, and thus to measure sustainable income, in the case when consumption is constant and the only determinant of utility.
} 
Proposition 6. The time premium (Weitzman [49])

Extra assumption. The interest rate $R$ is constant.

Result. Augmented GNNP equals GNNP $Y$ plus a 'time premium':

$Y^{\dagger}(t)=Y(t)\{1+\chi(t) /[R-\Gamma(t)]\}$,

where $\quad \Gamma(t):=\int_{t}^{\infty} \dot{Y}(s) e^{-R(s-t)} d s / \int_{t}^{\infty} Y(s) e^{-R(s-t)} d s$

is the time-averaged overall growth rate of GNNP,

and $\quad \chi(t):=\int_{t}^{\infty}[\partial Y(s) / \partial s] e^{-R(s-t)} d s / \int_{t}^{\infty} Y(s) e^{-R(s-t)} d s$

is the time-averaged growth in GNNP due to time alone.

Proof. Writing $\int_{t}^{\infty} Y(s) e^{-R(s-t)} d s=\Omega(t)$, from (15), (8) and (25),

$$
\begin{aligned}
Y(t)=\int_{t}^{\infty} R \mathbf{P}(s) \cdot \mathbf{C}(s) e^{-r(s-t)} d s & =\int_{t}^{\infty}[R Y(s)-\dot{Y}(s)] e^{-r(s-t)} d s \\
& =[R-\Gamma(t)] \Omega(t) .
\end{aligned}
$$

Hence from (18), (23) and (26),

$$
Y^{\dagger}(t)=Y(t)\left\{1+Q^{t}(t) / Y(t)\right\}=Y(t)\{1+\chi(t) \Omega(t) /[R-\Gamma(t)] \Omega(t)\} .
$$

We call $\chi(t) /[R-\Gamma(t)]$ the 'time premium,' rather than Weitzman's 'technological progress premium', because it is the value of all time-dependent shifts in the production set, in an open as well as a closed economy, as will be illustrated in Proposition $7 .^{7}$ If $\Gamma$ and $\chi$, the rates of overall GNNP growth and of GNNP growth due to time alone, are both constant, Propositions 4 and 6 yield simpler tests of unsustainability:

$$
\mathbf{Q}(t) \cdot \mathbf{I}(t) \leqslant-Y(t) \chi /(R-\Gamma) \text { or } \dot{Y}(t) \leqslant 0 \Rightarrow U(t)>U^{m}(t) .
$$

In practice, the basis of most empirical measurements of sustainability is $\mathbf{Q} \cdot \mathbf{I}$, net investment without the value of time $Q^{t}$. Weitzman [49] and Vincent et al. [47] are the only papers we know that include the time premium $\chi /(R-\Gamma)$ in their calculations. From (27), provided $\chi>0$, unsustainability is less likely than indicated by the $\mathbf{Q} \cdot \mathbf{I} \leqslant 0$ test that applies when $\chi=0$; but the $\dot{Y}(t) \leqslant 0$ test is unchanged, in that any non-positive growth rate of GNNP still implies unsustainability. Weitzman estimated $\chi /(R-\Gamma)$ to be about +0.4 for the USA, and the natural resource components of $\mathbf{Q} \cdot \mathbf{I}$ to be only about -0.03 of $Y$. However, Hamilton et al. [17] suggested that some of $\chi /(R-\Gamma)$ could be endogenous technical progress.

\footnotetext{
${ }^{7}$ Even if technological progress is the only time-dependent shift in production, $\chi$ is not what is commonly understood as the rate of technological progress (Pezzey [34]).
} 
Next, Proposition 7 shows how the value of time $Q^{t}$ can be measured when it is terms of trade rather than technology that are changing.

Proposition 7. Accounting for changing export prices in a solely resource-exporting economy (Vincent et al. [47]).

Extra assumptions: The economy owns foreign capital $K(t)$, which earns a world real interest rate $R$, and a non-renewable resource stock $\Sigma(t)$, whose depletion at rate $V(t)$ (so $\dot{\Sigma}=-V$ ) is exported at a time-varying, exogenous world price $Q^{V}(t)$. Export earnings $Q^{V} V$ are all spent on goods imports, which go either to consumption $C(t)$ or to resource extraction costs $X(V(t))$; so capital increases as $\dot{K}=R K+Q^{V}(t) V-C-X(V)$. Utility is just $U(C)$.

Result. Augmented net investment in the above economy is

$$
\mathbf{Q}^{\dagger}(t) \cdot \mathbf{I}^{\dagger}(t)=\dot{K}-\left[Q^{V}(t)-X_{V}\right] V+\int_{t}^{\infty} \dot{Q}^{V}(s) V(s) e^{-R(s-t)} d s .
$$

Proof. $\mathbf{Q}^{\dagger} \cdot \mathbf{I}^{\dagger}=\dot{K}-Q^{\Sigma} V+Q^{t}$; so we need the shadow prices $Q^{\Sigma}$ and $Q^{t} \cdot Q^{\Sigma}=Q^{V}(t)-X_{V}$ comes from setting $\partial H / \partial V=0$, where $H$ is the current value Hamiltonian $H=U(C)+$ $\Psi^{K}\left[R K+Q^{V}(t) V-C-X(V)\right]-\Psi^{\Sigma} V$, and then computing $Q^{\Sigma}=\Psi^{\Sigma} / \Psi^{K} . Q^{t}$ comes from (23), noting that $Y=C+\dot{K}+Q^{\Sigma} \dot{\Sigma}=R K+Q^{V}(t) V-X(V)-Q^{\Sigma} V$, so that $\partial Y(t) / \partial t=$ $\dot{Q}^{V}(t) V$.

Using the augmented Hartwick rule (22) with (28) and rearranging then gives the main result (8) of [47].

\section{Including population growth}

Despite its obvious importance in many developing countries, until two recent contributions mentioned shortly, population growth has received very little formal attention in the theory of sustainability measurement. So we consider here what adjustments to our sustainability tests are needed when population is growing. A full enquiry would be complex, and we deal only with the case of a constant, exogenous rate of growth, thus avoiding problems of endogenous growth, or varying, exogenous growth. Our result for this restricted case will not be surprising, but it still requires careful reasoning. Assuming constant growth forever is a poor description of the real world, as noted by Arrow et al. [4, p. 219]; but it is needed here so that population growth does not change the essential form of (19), and so that we keep a constant effective discount rate to use in proving Proposition 8 below, our adjusted sustainability result.

As noted earlier, population affects the welfare maximand as well as production. If population is $N(t)$, society's utility is generally some function of $(\mathbf{C}, N)$, rather than $U(\mathbf{C})$, and the production set is some $S(\mathbf{K}, N, t)$ rather than $S(\mathbf{K}, t)$. It would be neat if our theory could include this case by just treating $(\mathbf{C}, N)$ rather than $\mathbf{C}$ as arguments of a total utility function $U(\mathbf{C}, N)$. 
However, this does not work, and separate treatment is needed, for two reasons. First, because $N$ is exogenous and not a choice variable, any function $U(\mathbf{C}, N)$ is directly time-dependent, which invalidates key steps in AW's theory. Second, we assume that typically what society might wish to sustain is not total utility $U(\mathbf{C}, N)$, but some other, individual utility function, say $u(\mathbf{C}, N)$, while total utility is some population weighting function $G(N)$ multiplied by $u(\mathbf{C}, N)$. We then rewrite the intertemporal welfare maximisation (1) as

$$
\operatorname{Max} W\{\mathbf{C}(t)\}:=\int_{0}^{\infty} G(N(t)) u(\mathbf{C}(t), N(t)) e^{-\rho t} d t .
$$

An example of this framework is the maximand in Stiglitz [44, p. 132], where $\mathbf{C}=C$ (scalar), $G(N)=N, N(t)=e^{n t}$, and $u(\mathbf{C}, N)=u(c)=c^{\mu} / \mu$, where $c:=C / N$. Using $G(N)=N$ is a standard ethical assumption when growth is exogenous, but our formal treatment allows for other possibilities.

The two recent papers of relevance are [4] noted above, and Asheim [8]. Both are more general than our treatment by allowing for non-exponential population growth; but both omit the nonautonomous case, and give results for the sign of welfare change, $\dot{W}(t)$, rather than for sustainability. Note also the potential confusion that Arrow et al. define sustainability at $t$ as $\dot{W}(t)>0$. Following (10), we instead define maximum sustainable utility and sustainability in a growing population respectively as:

$$
u^{m}(t):=\max u \text { s.t. } u(\mathbf{C}(s), N(s)) \geqslant u \text { for all } s \geqslant t
$$

the economy is sustainable at time $t \Leftrightarrow u(t) \leqslant u^{m}(t)$.

It is hard to analyse sustainability in problem (29), for the time-dependence reason stated earlier, so we make further restrictive assumptions:

$N(t)=e^{n t}, \quad n>0$, a constant growth rate as envisaged;

$G(N)=N^{\zeta}, \quad 0 \leqslant \zeta \leqslant 1$, a constant; hence $G(N) e^{-\rho t}=e^{-(\rho-\zeta n) t} ;$

$u(\mathbf{C}, N)=u(\mathbf{c})$ where $\mathbf{c}:=\mathbf{C} / N=\mathbf{C} e^{-n t} ;$

$S(\mathbf{K}, N, t)$ exhibits constant returns to scale, that is, if $(\mathbf{C}, \mathbf{I}) \in S(\mathbf{K}, N, t)$,

then $(a \mathbf{C}, a \mathbf{I}) \in S(a \mathbf{K}, a N, t)$ for any $a>0$. We can then write

$(\mathbf{c}, \mathbf{i}) \in \tilde{S}(\mathbf{k}, t)$ where $\mathbf{k}:=\mathbf{K} / N$ and $\mathbf{i}:=\mathbf{I} / N=\dot{\mathbf{k}}+n \mathbf{k}$.

Note in (35) the use of both lower case and tilde labels for individual variables, as convenient ( $s$ is a time variable, so using it for $\tilde{S}$ here would cause confusion). Also note the introduction of $n \mathbf{k}$, the rate of population growth times per capita stocks, a generalisation of a term in the 'fundamental equation of neoclassical economic growth', Eq. (6) in Solow [41]. Assumptions (32)-(35) are not as restrictive as Stiglitz's, and exponential population growth (in (32)) and a constant returns technology (in (35)) are common assumptions in economic growth modelling. We have added some generality in the variable population weight $\zeta$ in (33), and multiple consumption goods $\mathbf{c}$ in (34). Moreover, Propositions 5 and 6 in [8], developed independently of 
the analysis here, indicate that a lengthier analysis than ours, using techniques in [4], could derive one-sided sustainability tests for non-exponential population growth. ${ }^{8}$

However, the above assumptions do exclude two common features of environmental resources. Any public good like environmental quality is excluded by (34), since it is the total rather than per capita amounts of such goods that affect individual utility. Most renewable resources, the growth of which does not exhibit constant returns to scale, are excluded by (35). For example, the wellknown logistic growth function has a quadratic rather than linear dependence on the resource stock (assuming the carrying environment cannot be replicated).

We made assumptions (32)-(35) because they allow us to eliminate population $N$ as an explicit variable. Moreover, we can do so in two different ways, with individual or total variables, as follows. With individual variables, the intertemporal optimisation problem becomes:

$$
\begin{array}{ll}
\underset{\mathbf{c}, \mathbf{i}}{\operatorname{iax}} & W\{\mathbf{c}(t)\}:=\int_{0}^{\infty} u(\mathbf{c}(t)) e^{-(\rho-\zeta n) t} d t \\
\text { s.t. } & {[\mathbf{c}(t), \mathbf{i}(t)] \in \tilde{S}[\mathbf{k}(t), t] ;}
\end{array}
$$

the effective utility discount rate is changed from $\rho$ to $\rho-\zeta n$; and using (35), the current-value Hamiltonian of this problem is

$$
\tilde{H}\left(\mathbf{c}, \mathbf{i} ; \tilde{\mathbf{\Psi}}, \Psi^{t}\right)=u(\mathbf{c})+\tilde{\mathbf{\Psi}} \cdot(\mathbf{i}-n \mathbf{k})+\psi^{t} .
$$

But the same problem, with exactly the same development path as a solution, can also be formulated in terms of total variables, as

$$
\begin{array}{cl}
\underset{\mathbf{C}, \mathbf{I}}{\operatorname{Max}} & W\{\mathbf{C}(t)\}:=\int_{0}^{\infty} e^{n t} u\left(\mathbf{C}(t) e^{-n t}\right) e^{-[\rho+(1-\xi) n] t} d t \\
\text { s.t. } & {\left[\mathbf{C}(t) e^{-n t}, \mathbf{I}(t) e^{-n t}\right] \in \tilde{S}\left[\mathbf{K}(t) e^{-n t}, t\right]}
\end{array}
$$

with effective discount rate now $\rho+(1-\zeta) n$, and current-value Hamiltonian

$$
H\left(\mathbf{C}, \mathbf{I} ; \boldsymbol{\Psi}, \Psi^{t}\right)=e^{n t} u\left(\mathbf{C} e^{-n t}\right)+\boldsymbol{\Psi} \cdot \mathbf{I}+\Psi^{t} .
$$

Applying the maximum principle of control theory to the optimisations (36) and (38), and using the fact that the production possibilities set $\tilde{S}$ is smooth, we conclude that the consumptioninvestment pair $\left(\mathbf{c}^{*}, \mathbf{i}^{*}\right)$ maximises $\tilde{H}$ under investment prices $\tilde{\boldsymbol{\Psi}}$, while the pair $\left(\mathbf{C}^{*}, \mathbf{I}^{*}\right)$ maximises $H$ under prices $\boldsymbol{\Psi}$. Because the ratio of all relevant variables across the two models is the same $\left(e^{n t}\right)$, this can happen if and only if the prices are the same:

$$
\left.\tilde{\boldsymbol{\Psi}}=\boldsymbol{\Psi} \text { (but in general } \psi^{t} \neq \Psi^{t} \text { unless } n=0\right) .
$$

(One can check that the co-state equations for (37) and (39) are consistent with this as follows. $\boldsymbol{\Psi}=\tilde{\boldsymbol{\Psi}}$ means that $\tilde{H}=H e^{-n t}-n \boldsymbol{\Psi} \cdot \mathbf{k}-\Psi^{t} e^{-n t}+\psi^{t}$. So $\nabla_{k} \tilde{H}=\nabla_{K} H-n \boldsymbol{\Psi}=[\rho+(1-\zeta) n] \boldsymbol{\Psi}-$ $\dot{\boldsymbol{\Psi}}-n \boldsymbol{\Psi}=(\rho-\zeta n) \boldsymbol{\Psi}-\dot{\boldsymbol{\Psi}}$, the correct costate equation for $\mathbf{k}$.) So from definition (4), real investment prices are the same in terms of total and individual variables:

$$
\tilde{\mathbf{Q}}(t)=\mathbf{Q}(t) \text {. }
$$

\footnotetext{
${ }^{8}$ I thank Geir Asheim for this observation, and also for noting that assumption (34), which is more general than my original, suffices for my results.
} 
Also from (4), real consumption prices in either formulation are the same:

$$
\tilde{\mathbf{P}}(t):=\left[\nabla u\left(\mathbf{C}^{*} e^{-n t}\right)\right] /[\lambda(t) \pi(t)]=\left[\nabla u\left(\mathbf{c}^{*}\right)\right] /[\lambda(t) \pi(t)]=: \mathbf{P}(t),
$$

while expression (6) for the real interest rate in terms of total variables must be adapted here to allow for the different effective discount rate in (38):

$$
R=\rho+(1-\zeta) n-\dot{\lambda} / \lambda-\dot{\pi} / \pi \text {. }
$$

AW's Lemma 1 for the optimal $\left(^{*}\right)$ individual economy is then

$$
\left[\nabla_{\mathbf{c}} U\left(\mathbf{c}^{*}\right)\right] \cdot \dot{\mathbf{c}}^{*}+(d / d t)\left(\tilde{\mathbf{\Psi}} \cdot \dot{\mathbf{k}}^{*}+\psi^{t}\right)=\dot{\tilde{H}}=(\rho-\zeta n)\left(\tilde{\mathbf{\Psi}} \cdot \dot{\mathbf{k}}^{*}+\psi^{t}\right) .
$$

Dividing by $\lambda(t) \pi(t)$, and using (41)-(43) and the Divisia condition $\dot{\mathbf{P}} \cdot \mathbf{c}^{*}=0$ derived from (5), establishes after a couple of lines of algebra that

$$
(d / d t)\left(\mathbf{P} \cdot \mathbf{c}^{*}+\mathbf{Q} \cdot \dot{\mathbf{k}}^{*}+q^{t}\right)=(R-n)\left(\mathbf{Q} \cdot \dot{\mathbf{k}}^{*}+q^{t}\right) \text { where } q^{t}:=\psi^{t} / \lambda \pi .
$$

The adjusted interest rate $R-n$ here is a fairly standard feature in per capita growth accounting (see for example, McKibben and Wilcoxen [24, Eq. (4)]), and we assume that it is positive.

Lastly, GNNP, augmented GNNP and augmented net investment are defined in terms of individual variables, using (41) and (42), as

$$
\begin{aligned}
& y(t):=\mathbf{P}(t) \cdot \mathbf{c}^{*}(t)+\mathbf{Q}(t) \cdot \dot{\mathbf{k}}^{*}=\mathbf{P}(t) \cdot \mathbf{c}^{*}(t)+\mathbf{Q}(t) \cdot\left[\mathbf{i}^{*}(t)-n \mathbf{k}^{*}(t)\right] ; \\
& y^{\dagger}(t):=y(t)+q^{t}(t) ; \quad \text { and } \\
& \tilde{\mathbf{Q}}^{\dagger}(t) \cdot \dot{\mathbf{k}}^{\dagger *}(t)=\mathbf{Q}(t) \cdot\left[\mathbf{i}^{*}(t)-n \mathbf{k}^{*}(t)\right]+q^{t}(t), \quad \text { where } \\
& \tilde{\mathbf{Q}}^{\dagger}:=\left(\mathbf{Q}, q^{t}\right) \text { and } \dot{\mathbf{k}}^{\dagger *}:=\left(\dot{\mathbf{k}}^{*}, 1\right) .
\end{aligned}
$$

Eq. (45) thus becomes the equivalent of (19) in terms of individual variables:

$$
\dot{y}^{\dagger}=(R-n) \tilde{\mathbf{Q}}^{\dagger} \cdot \dot{\mathbf{k}}^{\dagger *} \text {. }
$$

The entire AW theory outlined in Section 2.1, and 'augmented' in Section 3 for exogenous changes in production possibilities, can now be applied to the economy defined by (30)-(36) and (46)-(48). Because sustainability is defined by (31) in terms of individual utility $u$, Proposition 4's sustainability test also applies, as long as it is stated in terms of individual, not total, variables. We have then established the main result of this section:

Proposition 8. Tests for (individual) unsustainability with population growth

Extra assumption. Eqs. (30)-(35); the optimal development path that solves (36) and (38) is unique and has non-constant individual utility; and $R(t)>n$.

Result. At any time $t$, if either augmented, individual net investment, or the change in augmented, individual GNNP, is not positive, then the economy is individually unsustainable at that time:

$$
\begin{aligned}
& \mathbf{Q}(t) \cdot\left[\mathbf{i}^{*}(t)-n \mathbf{k}^{*}(t)\right]+q^{t}(t) \leqslant 0 \quad \text { or } \quad \dot{y}(t)+\dot{q}^{t}(t) \leqslant 0 \\
& \quad \Rightarrow u^{*}(t)>u^{m}(t) .
\end{aligned}
$$


Rewriting Proposition 5 using individual variables (hence using (49) not (19)) gives the individual value of time $q^{t}$, which in general differs from $Q^{t}$ :

$$
q^{t}(t):=\int_{t}^{\infty}[\partial y(s) / \partial s] \exp \left\{-\int_{t}^{s}\left[R\left(s^{\prime}\right)-n\right] d s^{\prime}\right\} d s .
$$

The significance of Proposition 8 for practical measurements is seen by multiplying each test by population $N(t)$ (dropping time dependences for neatness). The first test of individual unsustainability then becomes:

$$
\mathbf{Q} \cdot \mathbf{I}^{*}-n \mathbf{Q} \cdot \mathbf{K}^{*}+N q^{t} \leqslant 0 \text {. }
$$

Similarly, $N y^{\dagger}=Y-n \mathbf{Q} \cdot \mathbf{K}^{*}+N q^{t}$, so $y^{\dagger}=\left(Y-n \mathbf{Q} \cdot \mathbf{K}^{*}+N q^{t}\right) / N$, which transforms the second unsustainability test to:

$$
(d / d t) \ln \left(Y-n \mathbf{Q} \cdot \mathbf{K}^{*}+N q^{t}\right) \leqslant n .
$$

In both cases, a correct (un)sustainability measure entails two adjustments to the original, unaugmented measure $\mathbf{Q} \cdot \mathbf{I}^{*}$ or $Y$ in total units. First, the population growth rate $n$ times total stock value $\mathbf{Q} \cdot \mathbf{K}^{*}$ is deducted. Second, population $N$ times the individual value of time $q^{t}$ is added, not the total value of time $Q^{t}$. $q^{t}$ reflects non-population, exogenous changes in the production set, whereas $Q^{t}$ also includes the value to production of population growth. Both $n \mathbf{Q} \cdot \mathbf{K}^{*}$ and $N q^{t}$ adjustments, especially the latter, will be hard to measure in practice, but they exist nonetheless.

\section{Theoretical conclusions, practical difficulties and philosophical reflections}

By applying recent developments in the theory of national income and welfare measurement in a representative-agent, deterministic, optimal (i.e. present-value-maximising) economy with constant population, constant production possibilities and multiple consumption goods, we have derived two fairly general, one-sided tests for the unsustainability of such an economy. If the value of net investment is momentarily zero or negative, or if green net national product (GNNP) is momentarily constant or falling, then at that moment the economy is unsustainable, meaning that its current level of utility cannot be sustained forever. The 'green' in GNNP means that all environmental stocks and flows are included in the measure, as they are too in 'net investment' (also known as 'genuine savings'). There is no corresponding test for sustainability; and if the interest rate is constant, then constant wealth (defined as the value of future consumption) generally implies unsustainability. Moreover, an economy with a future, unsustainable peak of development must go through a period before the peak when net investment and GNNP change send a false message, by being strictly positive when the economy is in fact unsustainable.

All these results can be extended to apply to economies where production possibilities change exogenously over time, whether from changes to technology, terms of trade, or population. The basic extension is to 'augment' both net investment and GNNP by adding a term we call the 'value of time', which measures the value of future exogenous changes to production possibilities. This includes the effects of technical progress and/or changes in terms of trade, and was used to show how existing models of national accounting for such effects are special cases of our more general 
result. The extension to include population growth is more tricky, assuming that sustainability is defined in terms of individual utility. By assuming exponential growth and making other restrictions, we showed that to get an unsustainability indicator, dividing either augmented net investment or augmented GNNP change by population is not enough. Further adjustments, including a deduction of the population growth rate times the total value of stocks, are necessary. Our restrictions excluded environmental public goods and most renewable resources, so accounting for these features when population is growing remains an important problem for further work, as does extending the entire analysis to stochastic economies.

This paper offers a choice of two theoretical sustainability tests, but the practical difficulties with either are undoubtedly greater than past alternatives, due to the former's greater scope. Dollar values must be estimated for all significant environmental resources, and the price of produced consumption itself must also be estimated over time, in terms of an extended index of consumption and environmental goods. The tests also require estimations of future, exogenous changes in production possibilities, whether from technical progress, changing terms of trade, or population growth. One can only hope that, as has happened before in national accounting, advances in theory that are impractical when first proposed stimulate developments in measurement that make them more workable.

It seems also worth mentioning some generic but often-overlooked practical and philosophical difficulties faced by the broader and now common neoclassical approach to sustainability measurement, of which this paper is part, which can be traced back at least to Solow [42]. The practical difficulty is that significant externalities and other departures from competitiveness mean that current prices and quantities observed in the market, including those estimated with nonmarket valuation techniques for the externalities, may be significantly different from the optimal prices used by our theory. An obvious topic for further work is thus to extend our above results to imperfect economies, following recent developments by Aronsson and Lofgren [2] and Arrow et al. [3].

The philosophical limitation of the tests is that it remains a paradox why sustainability should be of interest in a present-value-maximising economy. The implicit assumption of most neoclassical sustainability measurement is that the goal of policy intervention is PV-maximisation, but subject to a sustainability constraint, or modified by a public sustainability concern. Why should the government be interested in sustainability, and use intervention if necessary to achieve it (as analysed by Pezzey [35]), if private agents merely wish to maximise PV? For consumers, maximising PV has generally nothing to do with sustainability. PV-maximisation gives a complete and unique prescription for the time paths of every decision that ever has to be made in the economy; and it can cause sustainability problems, because of the assumed constancy of the discount rate (Dasgupta and Heal [14]). Indeed, individuals must in fact believe there will be no policy intervention in favour of sustainability, or else they would modify their plans for the future, causing prices today not to be PV-optimal. So there is no apparent motive for using our Propositions 1, 4 or 8 to test for sustainability on a PV-optimal path, or for using intervention if unsustainability is thereby found. ${ }^{9}$

\footnotetext{
${ }^{9}$ The apparent paradox is not as direct in an overlapping generations context. Society may have a view on distributing resources across generations to achieve an intergenerational sustainability objective, but this need not imply a constraint on any generation's maximisation of PV over its own, finite lifetime.
} 
One resolution of this paradox is to follow Asheim et al. [9], who used an intergenerational equity axiom to find a rigorous justification of sustainability as a side constraint on maximising PV. Another resolution, not requiring an explicit concern for equity, would lie in some kind of split between private and public concerns about the future, along the lines of Marglin [23]. We could assume that the individual chooses his or her own actions to maximise some form of present value, but votes for a government which applies a sustainability concern both by testing for sustainability, and taking action to achieve it if necessary. One good reason for such an apparently schizophrenic stance would be that individuals cannot provide personally for their distant descendants, because of the mixing of bequests that occurs over several generations. This point has been noted verbally by Daly and Cobb [13, p. 39] and Howarth and Norgaard [22, p. 351], and formal modelling might produce a firm basis for treating 'sustainability' as itself a public good, and hence a valid concern of government policy.

\section{Acknowledgments}

I owe a special debt of gratitude to Geir Asheim for a wealth of careful, constructive correspondence. I also thank two anonymous referees, Bob Cairns, Kirk Hamilton, Nick Hanley, John Hartwick, Rich Howarth, Pamela Mason, Malcolm Pemberton, Robert Solow, Mike Toman, David Ulph, Martin Weitzman, Cees Withagen and many seminar participants for comments on several previous versions; and the UK Economic and Social Research Council's Global Environmental Change Research Initiative for Award L320-27-3002, under which early parts of this research were carried out. All remaining errors and omissions are mine.

\section{Appendix}

\section{Proof of Proposition 5.}

$$
\begin{aligned}
Y^{\dagger}\left(\mathbf{K}^{\dagger}, \mathbf{Q}^{\dagger}\right) & :=\max \mathbf{P} \cdot \mathbf{C}+\mathbf{Q}^{\dagger} \cdot \mathbf{I}^{\dagger} \quad \text { for }(\mathbf{C}, \mathbf{I}) \in S\left(\mathbf{K}^{\dagger}\right), \quad \text { so from }(19) \\
R_{\mathbf{Q}^{\dagger} \cdot \mathbf{I}^{\dagger}} & =(d / d t)\left[Y^{\dagger}\left(\mathbf{K}^{\dagger}, \mathbf{Q}^{\dagger}\right)\right]=\left(\partial Y^{\dagger} / \partial \mathbf{K}^{\dagger}\right) \cdot \mathbf{I}^{\dagger}+\left(\partial Y^{\dagger} / \partial \mathbf{Q}^{\dagger}\right) \cdot \dot{\mathbf{Q}}^{\dagger} \\
& =\left(\partial Y^{\dagger} / \partial \mathbf{K}^{\dagger}\right) \cdot \mathbf{I}^{\dagger}+\dot{\mathbf{Q}}^{\dagger} \cdot \mathbf{I}^{\dagger}
\end{aligned}
$$

Since this is true for any general $\mathbf{I}^{\dagger}$, for all components with $\dot{K}_{j}^{\dagger} \neq 0$,

$$
R Q_{j}^{\dagger}-\dot{Q}_{j}^{\dagger}=\partial Y^{\dagger} / \partial K_{j}^{\dagger}
$$

Since $\dot{t}=1, \dot{K}_{j}^{\dagger} \neq 0$ for the time component of (A.1), which is

$$
R Q^{t}-\dot{Q}^{t}=\partial Y^{\dagger} / \partial t=\partial Y / \partial t=Y_{t}
$$

because $Q^{t}=Y^{\dagger}-Y$ has no exogenous time dependence. Integrating (A.2) from time $t$ to $\infty$ gives $Q^{t}(t)=\int_{t}^{\infty}[\partial Y(s) / \partial s] \exp \left[-\int_{t}^{s} R\left(s^{\prime}\right) d s^{\prime}\right] d s$, which is (23). 


\section{References}

[1] T. Aronsson, K.-G. Lofgren, Green accounting: what do we know and what do we need to know?, in: T. Tietenberg, H. Folmer (Eds.), The International Yearbook of Environmental and Resource Economics 1998/99, Edward Elgar, Cheltenham, 1998a.

[2] T. Aronsson, K.-G. Lofgren, Green accounting in imperfect market economies, Environ. Resource Econ. 11 (1998b) 273-287.

[3] K. Arrow, P. Dasgupta, K.-G. Maler, Evaluating projects and assessing sustainable development in imperfect economies, Environ. Resource Econ. 26 (2003a) 149-187.

[4] K. Arrow, P. Dasgupta, K.-G. Maler, The genuine savings criterion and the value of population, Econ. Theory 21 (2003b) 217-225.

[5] G.B. Asheim, Net National Product as an indicator of sustainability, Scand. J. Econ. 96 (1994) $257-265$.

[6] G.B. Asheim, Adjusting green NNP to measure sustainability, Scand. J. Econ. 99 (1997) 355-370.

[7] G.B. Asheim, Green national accounting: why and how?, Environ. Devel. Econ. 5 (2000) 25-48.

[8] G.B. Asheim, Green national accounting with a changing population, Econ. Theory 23 (2004) 601-619.

[9] G.B. Asheim, W. Buchholz, B. Tungodden, Justifying sustainability, J. Environ. Econ. Manage. 41 (2001) 252-268.

[10] G.B. Asheim, M.L. Weitzman, Does NNP growth indicate welfare improvement?, Econ. Lett. 73 (2001) $233-239$.

[11] G. Atkinson, R. Dubourg, K. Hamilton, M. Munasinghe, D. Pearce, C. Young, Measuring Sustainable Development: Macroeconomics and the Environment, Edward Elgar, Cheltenham, UK, 1997.

[12] K.A. Brekke, Economic Growth and the Environment: On the Measurement of Income and Welfare, Edward Elgar, Cheltenham, 1997.

[13] H.E. Daly, J.B. Cobb, For the Common Good: Redirecting the Economy Toward Community, the Environment and a Sustainable Future, Beacon, Boston, 1989.

[14] P.S. Dasgupta, G.M. Heal, The optimal depletion of exhaustible resources, Symposium on the Economics of Exhaustible Resources, Rev. Econ. Stud. 41 (1974) 3-28.

[15] K. Hamilton, Pollution and pollution abatement in the national accounts, Rev. Income Wealth 42 (1996) $13-33$.

[16] K. Hamilton, Defining income and assessing sustainability, Typescript, Environment Department, World Bank, Washington DC, 1997.

[17] K. Hamilton, G. Atkinson, D. Pearce, Savings rules and sustainability: selected extensions, First World Congress of Environmental and Resource Economists, Venice, Italy, June 1998.

[18] K. Hamilton, M. Clemens, Genuine savings rates in developing countries, World Bank Econ. Rev. 13 (1999) 333-356.

[19] N. Hanley, I. Moffatt, R. Faichney, M. Wilson, Measuring sustainability: a time series of alternative indicators for Scotland, Ecolog. Econom. 28 (1999) 55-73.

[20] J.M. Hartwick, Intergenerational equity and the investing of rents from exhaustible resources, Amer. Econ. Rev. 67 (1977) 972-974.

[21] J.M. Hartwick, Natural resources, national accounting and economic depreciation, J. Public Econ. 43 (1990) 291-304.

[22] R.B. Howarth, R.B. Norgaard, Intergenerational transfers and the social discount rate, Environ. Resource Econ. 3 (1993) 337-358.

[23] S.A. Marglin, The social rate of discount and the optimal rate of investment, Quart. J. Econ. 77 (1963) 95-111.

[24] W.J. McKibbin, P.J. Wilcoxen, The theoretical and empirical structure of the G-Cubed model, Econ. Modelling 16 (1999) 123-148.

[25] E. Neumayer, Weak versus Strong Sustainability: Exploring the Limits of Two Opposing Paradigms, Edward Elgar, Cheltenham, UK, 1999.

[26] D.W. Pearce, G.D. Atkinson, Capital theory and the measurement of sustainable development: an indicator of 'weak' sustainability, Ecolog. Econ. 8 (1993) 103-108.

[27] D. Pearce, A. Markandya, E.B. Barbier, Blueprint for a Green Economy, Earthscan, London, 1989. 
[28] D. Pearce, R.K. Turner, T. O'Riordan, N. Adger, G. Atkinson, I. Brisson, K. Brown, R. Dubourg, S. Fankhauser, A. Jordan, D. Maddison, D. Moran, J. Powell, Blueprint 3: Measuring Sustainable Development, Earthscan, London, 1993.

[29] M. Pemberton, D. Ulph, Measuring income and measuring sustainability, Scand. J. Econ. 103 (2001) 25-40.

[30] J. Pezzey, Sustainable Development Concepts: An Economic Analysis, Environment Paper No. 2, 1992, World Bank, Washington DC, 1992a.

[31] J. Pezzey, Sustainability: an interdisciplinary guide, Environ. Values 1 (1992b) 321-362.

[32] J. Pezzey, The optimal sustainable depletion of non-renewable resources, AERE Summer Workshop, Boulder, Colorado, and EAERE Annual Conference, Dublin, Ireland, 1994.

[33] J.C.V. Pezzey, Sustainability constraints versus 'optimality' versus intertemporal concern, and axioms versus data, Land Econ. 73 (1997) 448-466.

[34] J.C.V. Pezzey, Measuring technical progress in gross and net products, Econ. Lett. 78 (2003) 247-252.

[35] J.C.V. Pezzey, Sustainability policy and environmental policy, Scand. J. Econ. 106 (2004), forthcoming.

[36] J.C.V. Pezzey, M.A. Toman, Progress and problems in the economics of sustainability, in: T. Tietenberg, H. Folmer (Eds.), The International Yearbook of Environmental and Resource Economics 2002/3, Edward Elgar, Cheltenham, 2002.

[37] J.C.V. Pezzey, C.A. Withagen, The rise, fall and sustainability of capital-resource economies, Scand. J. Econ. 100 (1998) 513-527.

[38] R. Repetto, W. Magrath, M. Wells, C. Beer, F. Rossini, Wasting Assets: Natural Resources in the National Income Accounts, World Resources Institute, Washington, DC, 1989.

[39] J.A. Sefton, M.R. Weale, The net national product and exhaustible resources: The effects of foreign trade, J. Public Econ. 61 (1996) 21-47.

[40] R. Solorzano, R. de Camino, R. Woodward, J. Tosi, V. Watson, A. Vasquez, V. Villalobos, J. Jimenez, R. Repetto, W. Cruz, Accounts Overdue: Natural Resource Depreciation in Costa Rica, Tropical Science Centre, San Jose, Costa Rica, World Resources Institute, Washington, DC, USA, 1991.

[41] R.M. Solow, A contribution to the theory of economic growth, Quart. J. Econ. 70 (1956) 65-94.

[42] R.M. Solow, On the intergenerational allocation of natural resources, Scand. J. Econ. 88 (1986) 141-149.

[43] R.M. Solow, An almost practical step toward sustainability, Resources Pol. 19 (1993) 162-172.

[44] J.E. Stiglitz, Growth with exhaustible natural resources: Efficient and optimal growth paths, Symposium on the Economics of Exhaustible Resources, Rev. Econ. Stud. 41 (1974) 123-137.

[45] N. Vellinga, C. Withagen, On the concept of green national income, Oxford Econ. Pap. 48 (1996) 499-514.

[46] J.R. Vincent, Resource depletion and economic sustainability in Malaysia, Environ. Devel. Econ. 2 (1997) 19-37.

[47] J.R. Vincent, T. Panayotou, J.M. Hartwick, Resource depletion and sustainability in small open economies, J. Environ. Econ. Manage. 33 (1997) 274-286.

[48] M.L. Weitzman, On the welfare significance of national product in a dynamic economy, Quart. J. Econ. 90 (1976) $156-162$.

[49] M.L. Weitzman, Sustainability and technical progress, Scand. J. Econ. 99 (1997) 1-13. 